\title{
Effect of different bonding protocols on degree of monomer conversion and bond strength between orthodontic brackets and enamel
}

\section{Lorena Marques Ferreira de SENA ${ }^{(a)}$ Helga Adachi Medeiros BARBOSA(a) Sergei Godeiro Fernandes Rabelo CALDAS ${ }^{(a)}$ \\ Mutlu OZCAN(b) \\ Rodrigo Othávio de Assunção e SOUZA(a)}

(a) Universidade Federal do Rio Grande do Norte - UFRN, Department of Dentistry, Natal, RN, Brazil.

(b) University of Zurich, Department of Dental Materials, Zurich, Switzerland.

Presented at the Sociedade Brasileira de Pesquisa Odontológica Annual Meeting, 2017, Campinas, São Paulo, Brazil.

Declaration of Interest: The authors certify that they have no commercial or associative interest that represents a conflict of interest in connection with the manuscript.

Corresponding Author:

Rodrigo Othávio de Assunção e Souza

E-mail: rodrigoothavio@gmail.com

hitps://doi.org/10.1590/1807-3107bor-2018.vol32.0058
Abstract: The objective of the present study was to evaluate the effect of different surface treatments and polymerization protocols on the bond strength of brackets to enamel, and the degree of conversion of the bonding agents. 120 bovine crowns were embedded in acrylic resin blocks and sanded. Next, the blocks were randomly assigned into 12 groups. Metal brackets were bonded to enamel according to the "surface treatment" factor (A: Phosphoric Acid; ATxt: Phosphoric Acid + Transbond XT Primer ${ }^{\circledR}$; Tse: Transbond Plus Self Etching Primer ${ }^{\circledR}$; and SBU: Scotchbond Universal ${ }^{\circledR}$ ) and "polymerization" factor $\left(\mathrm{R}_{20}\right.$ : Radii-Cal ${ }^{\circledR} / 20$ seconds; $\mathrm{V}_{20}$ : Valo Cordless ${ }^{\circledR} / 20$ seconds; and $\mathrm{V}_{3}$ : Valo Cordless ${ }^{\circledR} / 3$ seconds). All samples were stored for 6 months (water, $37^{\circ} \mathrm{C}$ ) and then subjected to a shear bond strength test (SBS). Bond failures were classified according to the Adhesive Remnant Index (ARI) and analyzed with the Kruskal-Wallis and Mann-Whitney tests (5\%). Using the same factors, 120 resin discs were made to assess the degree of conversion (DC) of the monomer. Data from the SBS (MPa) and DC (\%) were analyzed by analysis of variance ( 2 factors) and Tukey's test ( $5 \%$ ). For the SBS, the factors "polymerization" $\left(\mathrm{R}_{20}=8.1^{\mathrm{B}} ; \mathrm{V}_{20}=13.2^{\mathrm{A}} ; \mathrm{V}_{3}=5.2^{\mathrm{C}}, \mathrm{p}=0.0001\right)$ and "surface treatment" $\left(\mathrm{A}=3.1^{\mathrm{C}} ; \mathrm{ATxt}=13.6^{\mathrm{A}}\right.$; $\left.\mathrm{Tse}=12.3^{\mathrm{A}} ; \mathrm{SBU}=6.3^{\mathrm{B}}, \mathrm{p}=0.0001\right)$ were statistically significant among groups. The highest adhesion value were found for the ATxt/ $V_{20}$ group $\left(22.2^{A}\right)$ and the lowest value for the $A / R_{20}$ group $\left(1.2^{\mathrm{E}}\right)$. Regarding ARI, score 2 was the most prevalent in groups $\mathrm{A}$, ATxt, $V_{20}$ and $V_{3}$, while score 4 was the most prevalent in the Tse, SBU and $R_{20}$ groups, with no significant difference between them $(p=1.0)$. Regarding $\mathrm{DC}$, the factors "polymerization" $\left(\mathrm{R}_{20}=66.6^{\mathrm{A}} ; \mathrm{V}_{20}=58.4^{\mathrm{B}} ; \mathrm{V}_{3}=45.1^{\mathrm{C}}, \mathrm{p}=0.0001\right)$ and "surface treatment" $\left(\mathrm{A}=52^{\mathrm{B}}, \mathrm{ATxt}=59.7^{\mathrm{A}}\right.$, Tse $=51.4^{\mathrm{B}}, \mathrm{SBU}=63.8^{\mathrm{A}}$, $p=0.0001)$ were statistically significant. Tse was more sensitive to the variations in polymerization protocols than the other surface treatments. Treatment A did not present suitable bond strength or degree of conversion.

Keywords: Adhesiveness; Dental Enamel; Orthodontic Brackets.

\section{Introduction}

Orthodontics has evolved considerably in recent decades improving

Submitted: February 02, 2018

Accepted for publication: May 07, 2018

Last revision: May 1 1, 2018 aspects such as treatment planning and diagnosis ${ }^{1}$, clinical performance ${ }^{2}$ and patient comfort. ${ }^{3,4}$ Factors that can influence clinical performance 
include bracket design and type ${ }^{5}$, composition of the orthodontic wire ${ }^{6}$, and, especially, the resins and adhesive systems used for bracket bonding. ${ }^{7,8}$ Adhesion failures between bracket and tooth surface compromise the success of the orthodontic treatment, are costly, and cause inconvenience to the patient. ${ }^{3}$

Bonding brackets to dental enamel is a routine procedure in Orthodontics and it usually follows the protocol proposed by Buonocore ${ }^{9}$ in which the enamel surface is conditioned with $37 \%$ phosphoric acid to increase adhesiveness. Although prior acid conditioning (conventional system) is still the most employed method, the use of self-etching (single step) adhesive systems has recently gain some interest. ${ }^{10}$ In addition to simplifying the procedure with consequent reduction of clinical time and greater standardization, self-conditioning systems have greater tolerance to moisture ${ }^{3}$ and possible antimicrobial properties due to the presence of adhesive monomers in their composition. ${ }^{11}$

To be clinically effective, self-conditioning systems must promote a satisfactory bond strength between brackets and enamel. Some authors ${ }^{12}$ have found that self-etching systems can have acceptable clinical performance in the bonding of orthodontic brackets compared to the conventional system. On the other hand, recent studies have proposed the bonding of metallic brackets to enamel without the use of adhesives, ${ }^{13,14}$ since a consensus seems to exist in the literature that a minimum adhesion force (6 to $8 \mathrm{MPa}$ ) is sufficient in certain cases, ${ }^{15}$ and that very a high adhesive strength may increase the risk of enamel fracture and pulp damage during bracket removal. ${ }^{16}$

Another factor that can influence adhesive resistance is the polymerization protocol. ${ }^{17} \mathrm{~A}$ multitude of lightcuring devices is currently available, with varying light intensities and polymerization times. ${ }^{18}$ For example, the

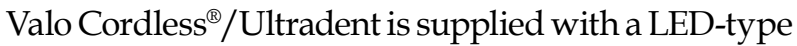
unit that includes an $x$ tra power mode of $3200 \mathrm{~mW} / \mathrm{cm}^{2}$ intensity. Because of these high-intensity light waves, some authors ${ }^{4,19}$ have suggested a 3- to 6-second polymerization for bracket bonding. Conventional polymerization units emit light intensities from 1000 to $1250 \mathrm{~mW} / \mathrm{cm}^{2}$ and are suitable for the bracket bonding with a time of 20 seconds per application. ${ }^{4}$

Based on the scientific literature, there is a wide diversity of protocols and clinical procedures for bonding orthodontic brackets, which makes it difficult for the clinician to make an informed decision. In addition, studies that compare different enamel surface treatments for metallic bracket bonding are lacking, and mostly performed using high intensity light curing units for short polymerization periods.

Therefore, the objective of this work was to evaluate the effect of different surface treatments and polymerization protocols on the bond strength between metallic brackets and enamel, and the degree of conversion of the bonding agents.

The hypotheses tested were: the adhesive strength of metallic brackets bonded to enamel and the degree of conversion of the bonding agents are influenced by the surface treatment and the polymerization protocol.

\section{Methods}

\section{Materials}

A description of the bonding materials of this study is shown in Table 1.

\section{Shear Bond Strength}

One hundred and twenty bovine lower incisors with intact crowns were selected. The soft tissue adhered to the roots was removed with periodontal curettes. The roots were separated from the crowns using a double-sided diamond disk mounted on a micromotor and straight handpiece and discarded. The crowns were then stored in distilled water at $4^{\circ} \mathrm{C}$ until the specimens were prepared (ISO 11405). ${ }^{20}$ The crowns were embedded in colorless chemically activated acrylic resin using a preformed rectangular mold made of industrial silicone. During insertion, the buccal surface of the crowns was in direct contact with the mold base, avoiding coating the surface with resin.

A 5-mm area of exposed enamel was flattened ${ }^{20}$ under constant water irrigation, using sand paper of different granulations (\# 200, 400 and 600) in a metal polisher/sander.

After flattening, dental prophylaxis was performed using a rubber cup, pumice stone, water and a micromotor in low rotation for ten seconds. Each rubber cup was used on a maximum of ten crowns. Lastly, the crowns were washed with water until complete removal of the pumice paste and dried 
Table 1. Bonding materials used in this study.

\begin{tabular}{|c|c|c|c|}
\hline Material/ Lot & Manufacturer & Composition & $\%$ per weight \\
\hline \multirow{6}{*}{$\begin{array}{l}\text { Transbond XT } \\
\text { Primer }^{\circledR} / \text { Lot } \\
\text { N682347 }\end{array}$} & \multirow{6}{*}{$\begin{array}{c}\text { 3M Unitek } \\
\text { (Monrovia, USA) }\end{array}$} & BisGMA & $45-55^{*}$ \\
\hline & & TEDMA & $45-55^{*}$ \\
\hline & & Triphenyl antimony & $<1^{*}$ \\
\hline & & (4dimethylamine) -benzenethanol) & $<0.5^{*}$ \\
\hline & & DLCaforquinone & $<0.3^{*}$ \\
\hline & & Hydroquinone & $<0.03^{*}$ \\
\hline \multirow{7}{*}{$\begin{array}{l}\text { Transbond Plus Self } \\
\text { Etching Primer }^{\circledR} / \text { Lot } \\
\text { B25723569486 }\end{array}$} & \multirow{7}{*}{$\begin{array}{c}\text { 3M Unitek } \\
\text { (St. Paul, USA) }\end{array}$} & 2-propenoic acid, 2-methyl, phosphonicobis (oxy-2,1-ethanediyl) ester & $25-40^{*}$ \\
\hline & & Water & \\
\hline & & Mono HEMA phosphate & $15-25^{*}$ \\
\hline & & Tri [2 (methacryloyloxy) ethyl] phosphate & $10-25^{*}$ \\
\hline & & DL-Caforquinone & $1-10^{*}$ \\
\hline & & $\mathrm{N}, \mathrm{N}$-Dimethylbenzocaine & $<3^{*}$ \\
\hline & & Dipotassium hexafluorotitanate & $<3^{*}$ \\
\hline \multirow{12}{*}{$\begin{array}{l}\text { Scotchbond } \\
\text { Universal }^{\circledR} / \text { Lot } \\
582958\end{array}$} & \multirow{12}{*}{$\begin{array}{c}\text { 3M Espe } \\
\text { (Sumaré, Brazil) }\end{array}$} & BisGMA & $15-25$ \\
\hline & & -Hydroxyethyl methacrylate & $15-25$ \\
\hline & & Decamethylene dimethacrylate & $11-15$ \\
\hline & & Water & $12-15$ \\
\hline & & Ethanol & $01-15$ \\
\hline & & silane treated silica & $05-15$ \\
\hline & & 1,10-Decanediol phosphate methacrylate & $01-10$ \\
\hline & & Acrylic copolymer and itaconic acid & $01-05$ \\
\hline & & 2-Dimethylaminoethyl methacrylate & $<2$ \\
\hline & & $\mathrm{N}, \mathrm{N}$-Dimethylbenzocaine & $<2$ \\
\hline & & Caforquinone & $<2$ \\
\hline & & Methyl ethyl ketone & $<0,5$ \\
\hline \multirow{5}{*}{$\begin{array}{l}\text { Transbond XT } \\
\text { Adhesive Paste }{ }^{\circledR} / \text { Lot } \\
\text { N686755 }\end{array}$} & \multirow{5}{*}{$\begin{array}{c}\text { 3M Unitek } \\
\text { (Monrovia, USA) }\end{array}$} & Treated silane quartz & $70-80 *$ \\
\hline & & BisGMA & 10-20* \\
\hline & & bisphenol A bis (2-hydroxyethyl ether) dimethacrylate & $5-10^{*}$ \\
\hline & & Treated silane silica & $<2^{*}$ \\
\hline & & Diphenyliodonium hexafluorophosphate & $<0,2^{*}$ \\
\hline
\end{tabular}

BisGMA: Bisphenol dimethacrylate A diglycidyl ether; TEGDMA: Dimethacrylate triethylene glycol; HEMA: 2-Hydroxyethyl methacrylate. ${ }^{*}$ The specific chemical identity and/or exact percentage (concentration) of this composition is maintained as a trade secret.

with air jets for 10 seconds. The area of the adhesive interface was delimited by placing an adhesive tape on the enamel with a circular hole of $4.5 \mathrm{~mm}$ diameter.

The 120 crowns were distributed according to the four types of surface treatment and three polymerization protocols, as shown in Figure 1.

For the phosphoric acid group (A group), the exposed enamel was conditioned with $37 \%$ Condac $37^{\circledR}$ phosphoric acid (FGM, Joinville, SC, Brazil) for 15 seconds. Afterwards, the surface was washed with a water jet ( 30 seconds) and dried with air jet for 5 seconds.

The phosphoric acid and the conventional Transbond XT Primer ${ }^{\circledR}$ adhesive system group (ATxt group) had the exposed enamel conditioned as A group. Next, theadhesive system was applied with a microbrush and the excess adhesive was removed with a light air jet for 2 seconds.
For the Transbond Plus Self Etching Primer ${ }^{\circledR}$ group (Tse group), the enamel surface was rubbed with the product for 3 seconds according to the manufacturer's recommendations. The excess adhesive was removed by a light air jet for 2 seconds.

For the Scotchbond Universal ${ }^{\circledast}$ self-etching adhesive system group (SBU group), the product was applied with a microbrush for 20 seconds and the excess removed with a light air jet for 5 seconds.

Bracket bonding was performed by the sameoperator in all samples. The base of Roth Light ${ }^{\circledR}$ lower incisor brackets (Morelli, Sorocaba, Brazil) was coated with Transbond XT light cure adhesive paste ${ }^{\circledR}$ and the bracket was positioned on the buccal face of the crowns, parallel to the long axis of the teeth. The excess resin around the brackets was removed with an exploratory probe. 


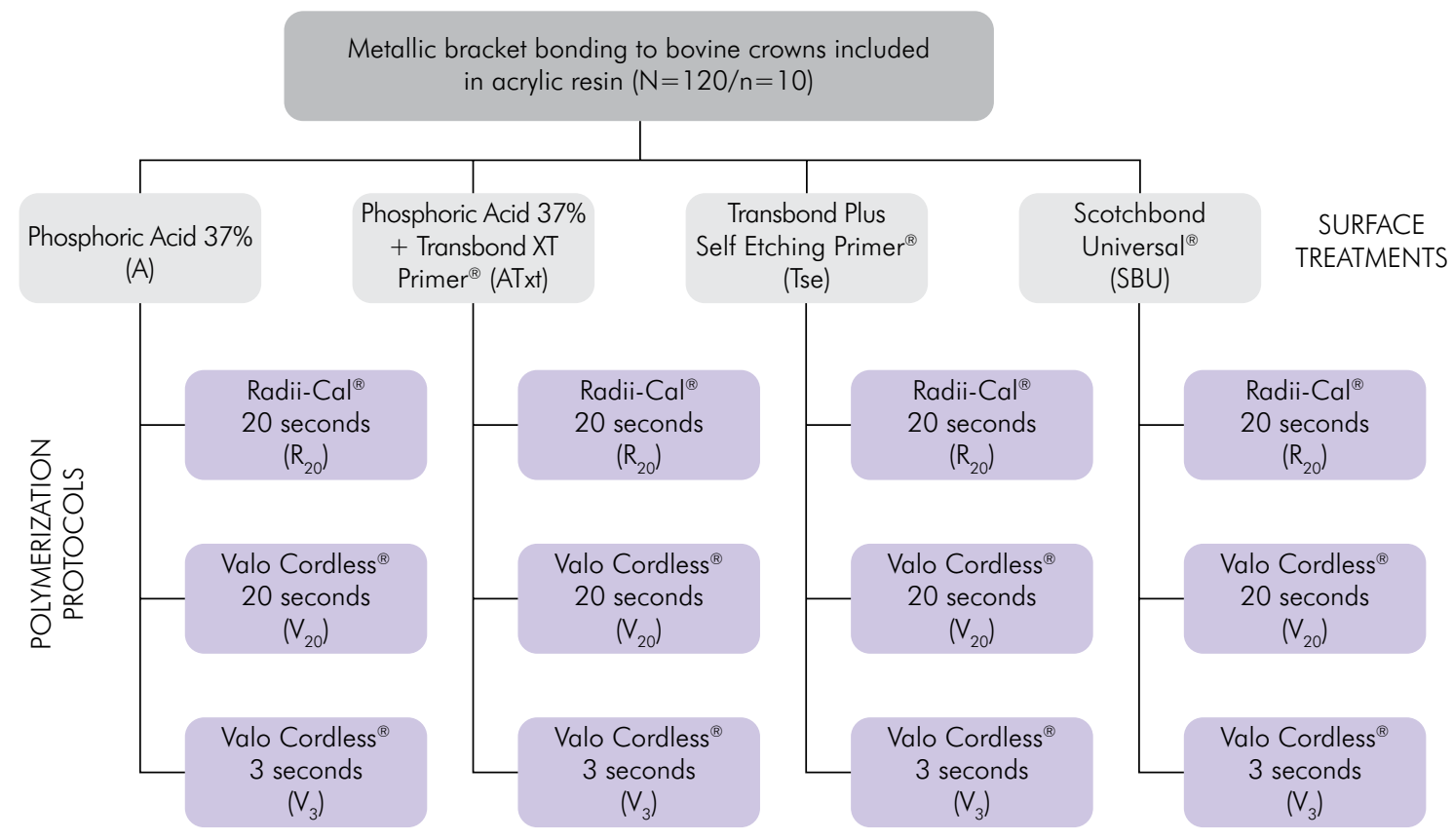

Figure 1. Flowchart indicating surface treatments and polymerization protocols performed during bracket bonding.

Three polymerization protocols were evaluated: Radii-Cal ${ }^{\circledR}$ (SDI, São Paulo, SP, Brazil) for 20 seconds $\left(\mathrm{R}_{20}\right.$ protocol), Valo Cordless ${ }^{\circledR}$ (Ultradent, South Jordan, Utah) for 20 seconds $\left(\mathrm{V}_{20}\right.$ protocol) and Valo Cordless $^{\circledR}$ for 3 seconds ( $\mathrm{V}_{3}$ protocol). The light was directed to the center of the bracket and the tip of the light-curing device touched the buccal surface of the bracket.

The specimens from the 12 groups were stored in distilled water $\left(37^{\circ} \mathrm{C}\right)$ for 6 months. After this period, the shear test was performed in a Shimadzu AGS- $X^{\circledast}$ universal testing machine (Shimadzu, Barueri, Brazil), in which a metal device secured the specimen so that the metal/enamel interface remained perpendicular to the horizontal plane. A blade was attached to the load cell $(300 \mathrm{Kgf})$ of the machine and applied to the metal/enamel interface at a constant speed of $1 \mathrm{~mm} / \mathrm{min}$ until fracture occurred.

The adhesive strength required to detach the bracket was given in Newton $(\mathrm{N})$ and converted to Megapascal (MPa) according to the following formula, with A being the base area of the bracket $\left(14 \mathrm{~mm}^{2}\right)$ :

$$
\mathrm{R}(\mathrm{MPa})=\frac{\mathrm{F}(\mathrm{N})}{\mathrm{A}\left(\mathrm{mm}^{2}\right)}
$$

\section{Failure type analysis: Adhesive Remnant Index (ARI)}

The types of failure were analyzed in a stereomicroscope (Nikon SMZ800, Tokyo, Japan) with a $25 \times$ magnification and classified according to the ARI proposed by Bishara and Trulove: ${ }^{21}$ score 1 all the resin stays on enamel, score 2 - more than $90 \%$ of the resin stays on enamel, score 3 - between 10 and $90 \%$ of the resin stays on enamel, score 4 less than $10 \%$ resin stays on enamel, and score 5 - no resin is observed on enamel. The rating was based on the evaluation of a single operator. Intra-examiner calibration was obtained with the Kappa Index from re-evaluation of $10 \%$ of the samples after 15 days.

\section{Degree of conversion}

One hundred and twenty resin discs ( $\mathrm{n}=10$ / group) with an average of $0.1 \mathrm{~mm}$ thickness and $5 \mathrm{~mm}$ diameter were made by a single operator to analyze the degree of conversion of the bonding agents tested in the shear bond strength test.

A $2 \mathrm{~mm}$ portion of the Transbond XT adhesive paste ${ }^{\circledR}$ was placed on a microscopy glass slide ( $26 \mathrm{~mm}$ x $76 \mathrm{~mm} \times 1 \mathrm{~mm}$ ) and covered with a polyester strip. Next, a metal orthodontic bracket identical to the 
one used in the previous test was pressed onto the polyester strip, simulating the light pressure applied clinically during bracket bonding. The samples were subjected to the same polymerization and light exposure protocols as used for the shear test $\left(\mathrm{R}_{20}, \mathrm{~V}_{20}\right.$ and $\left.\mathrm{V}_{3}\right)$. After removal of the bracket and the polyester strip, the discs were created and used to assess the degree of conversion corresponding to the A group (37\% phosphoric acid).

The above sequence was carried out 3 times, each time applying a drop of the Transbond XT Primer $^{\circledR}$, the Transbond Plus Self Etching Primer ${ }^{\circledR}$, or the Scotchbond Universal ${ }^{\circledR}$ adhesive system on the microscopy glass slide, prior to adhesive paste application. The originated specimens were used to assess the degree of conversion of the monomer in the groups ATxt, Tse and SBU.

All specimens were stored for 24 hours in dark Eppendorf tubes to prevent light exposure and complete the polymerization process. The degree of conversion analysis was done in a Fourier Transform/ FT-IR Infrared Spectrophotometer (IRAffinity- ${ }^{\circledR}$, Shimadzu, Tokyo, Japan) equipped with an attenuated total reflectance device (MIRacle HATR module with ZnSe, PIKE Technologies, Madison, USA).

The software used to measure spectra was the Shimadzu IRsolution $1.60^{\circledR}$ (Shimadzu Corporation, 2011). The results were initially normalized for baseline adjustment. All spectra were obtained under the following conditions: absorbance mode; 32 number of scans; 700 to $4000 \mathrm{~cm}^{-1}$ range; and $4 \mathrm{~cm}^{-1}$ resolution.

Since the predominant monomer in the Transbond XT Adhesive Paste ${ }^{\circledR}$ is BisGMA (Table 1), the degree of conversion (\%) was calculated by the band intensity ratio for the double bonds of the methacrylate group (with energy absorption in the $1637 \mathrm{~cm}^{-1}$ region, aliphatic peak) and the band intensity of the double aromatic bonds (with energy absorption in the $1608 \mathrm{~cm}^{-1}$ region, aromatic peak), using the following formula:

$$
\text { GC }(\%)=1-\left[\frac{R(1638 / 1608) \text { polymerized sample }}{R(1638 / 1608) \text { non-polymerized sample }}\right] \times 100
$$

In which $\mathrm{R}(1638 / 1608)$ represents the ratio of the values obtained for the most stable wavelength peaks (1638 $\mathrm{nm}$ and $1608 \mathrm{~nm}$ ).

\section{Power of the polymerization units}

The power of the light-curing units used in this study was measured by a single operator through the analogue radiometer Led-Kondortech ${ }^{\circledR}$ (Kondortech, São Carlos, SP, Brazil), with sensitivity varying from 0 to $3000 \mathrm{~mW} / \mathrm{cm}^{2}$. The units were fully charged during the measurement.

\section{Data analysis}

The database was built on the Statistix ${ }^{\circledR}$ software platform (Analytical Software Inc., version 8.0, 2003), and a significance level of $5 \%$ was considered in all cases. Sample power was calculated through the website www.openepi.com. Shear bond strength test results (MPa) and degree of conversion (\%) were evaluated descriptively, and compared through analysis of variance ( 2 factors) and the Tukey's test. The ARI results were analyzed descriptively and compared using the Kruskal-Wallis and Mann-Whitney tests.

\section{Results}

\section{Shear bond strength test}

The results of the 2 factors ANOVA for the experimental conditions are presented in Table 2. Mean bond strength values were significantly affected by the "polymerization" $(\mathrm{p}<0.05)$ and "surface treatment" $(p<0.05)$ factors. The interaction between the factors was also statistically significant $(\mathrm{p}<0.05)$.

The means and standard deviations of the experimental groups are presented in Table 3 and plotted in Figure 2. The $\mathrm{V}_{20}\left(13.271 \mathrm{MPa}^{\mathrm{A}}\right)$ protocol resulted in adhesive resistance valuesstatistically higher than $\mathrm{R}_{20}\left(8.146 \mathrm{MPa}^{\mathrm{B}}\right)$ and $\mathrm{V}_{3}\left(5.26 \mathrm{MPa}^{\mathrm{C}}\right)$, which were statistically different from each other. Regarding the

Table 2. Results of 2 factors ANOVA for the "polymerization" and "surface treatment" factors according to bond strength ( $\left.{ }^{*} p<0.05\right)$.

\begin{tabular}{lccccc}
\hline Factors & $\mathrm{GL}$ & $\mathrm{SQ}$ & $\mathrm{MQ}$ & $\mathrm{L}$ & $\mathrm{p}$ \\
\hline Polymerization & 2 & 1316.20 & 658.101 & 44.27 & $0.0001^{*}$ \\
Surface treatment & 3 & 2207.16 & 735.718 & 49.49 & $0.0001^{*}$ \\
Polymerization* & 6 & 1177.55 & 196.259 & 13.20 & $0.0001^{*}$ \\
surface treatment & 108 & 1605.56 & 14.866 & & \\
Error & 119 & 6306.47 & & & \\
Total & 119 &
\end{tabular}

GL: degrees of freedom; SQ: sum of squares; $M Q$ : mean squares; L: freedom. *Statistically significant difference at the $5 \%$ level. 
"surface treatment" factor, phosphoric acid followed by Transbond XT Primer ${ }^{\circledR}$ generated adhesive resistance values $\left(\mathrm{ATxt}=13.63 \mathrm{MPa}^{\mathrm{A}}\right)$ similar to Transbond Plus Self Etching Primer ${ }^{\circledR}\left(\right.$ Tse $\left.=12.38^{\mathrm{A}} \mathrm{MPa}\right)$, which were statistically higher than Scotchbond Universal ${ }^{\circledR}$ $\left(\mathrm{SBU}=6.37^{\mathrm{B}} \mathrm{MPa}\right)$ and phosphoric acid conditioning alone $\left(\mathrm{A}=3.18^{\mathrm{C}} \mathrm{MPa}\right)$. The highest bond strength results were obtained for the ATxt/ $\mathrm{V}_{20}\left(22.298 \mathrm{MPa}^{\mathrm{A}}\right)$, Tse/ $\mathrm{V}_{20}$ $\left(17.05 \mathrm{MPa}^{\mathrm{AB}}\right), \mathrm{Tse} / \mathrm{R}_{20}\left(15.33 \mathrm{MPa}^{\mathrm{B}}\right)$ and $\mathrm{ATxt} / \mathrm{R}_{20}(12.78$
$\mathrm{MPa}^{\mathrm{BC}}$ ) groups. The lowest values were obtained for the $\mathrm{A} / \mathrm{R}_{20}$ group $\left(1.27 \mathrm{MPa}^{\mathrm{E}}\right)$.

\section{Failure type analysis: Adhesive Remnant Index}

The intra-examiner agreement for failure type analysis was considered high $(\mathrm{k}=0.85)$. A significant difference $(p<0.05)$ in ARI scores prevalence was found for the comparisons between scores 1 and 4,1 and 2, 4

Table 3. Bond strength values (MPa) according to the factors "surface treatment" and "polymerization" $(\mathrm{n}=10)$.

\begin{tabular}{|c|c|c|c|}
\hline Group & Surface treatment & Polymerization & Mean $\pm \mathrm{DP}$ \\
\hline$A / R_{20}$ & & Radii $20 \mathrm{~s}$ & $1.27 \pm 0.81^{\mathrm{E}}$ \\
\hline $\mathrm{A} / \mathrm{N}_{20}$ & Phosphoric Acid 37\% & Valo $20 \mathrm{~s}$ & $5.28 \pm 3.74^{\mathrm{DE}}$ \\
\hline $\mathrm{AV}_{3}$ & & Valo $3 \mathrm{~s}$ & $2.99 \pm 1.26 \mathrm{DE}$ \\
\hline $\mathrm{AT} x t / \mathrm{R}_{20}$ & & Radii $20 \mathrm{~s}$ & $12.78 \pm 6.45^{B C}$ \\
\hline $\mathrm{ATxt} / \mathrm{N}_{20}$ & Phosphoric Acid 37\% + Transbond XT Primer ${ }^{\circledR}$ & Valo $20 \mathrm{~s}$ & $22.29 \pm 5.10^{A}$ \\
\hline $\mathrm{AT} x \mathrm{xt} / \mathrm{N}_{3}$ & & Valo $3 \mathrm{~s}$ & $5.81 \pm 3.78^{\mathrm{DE}}$ \\
\hline $\mathrm{Tse} / \mathrm{R}_{20}$ & & Radii $20 \mathrm{~s}$ & $15.33 \pm 7.08^{B}$ \\
\hline $\mathrm{Tse} / \mathrm{V}_{20}$ & Transbond Plus Self Etching Primer ${ }^{\circledR}$ & Valo $20 \mathrm{~s}$ & $17.05 \pm 8.26^{\mathrm{AB}}$ \\
\hline $\mathrm{Tse}_{\mathrm{se}}$ & & Valo $3 \mathrm{~s}$ & $4.75 \pm 1.80^{\mathrm{DE}}$ \\
\hline $\mathrm{SBU} / \mathrm{R}_{20}$ & & Radii $20 \mathrm{~s}$ & $3.18 \pm 1.25^{\mathrm{DE}}$ \\
\hline $\mathrm{SBU} / \mathrm{N}_{20}$ & Scotchbond Universal ${ }^{\circledR}$ & Valo $20 \mathrm{~s}$ & $8.44 \pm 3.31^{C D}$ \\
\hline $\mathrm{SBU} / \mathrm{N}_{3}$ & & Valo $3 \mathrm{~s}$ & $7.47 \pm 3.16 \mathrm{CD}$ \\
\hline
\end{tabular}

Tukey test $(p<0.05 \%)$. Equal letters indicate statistical similarity.

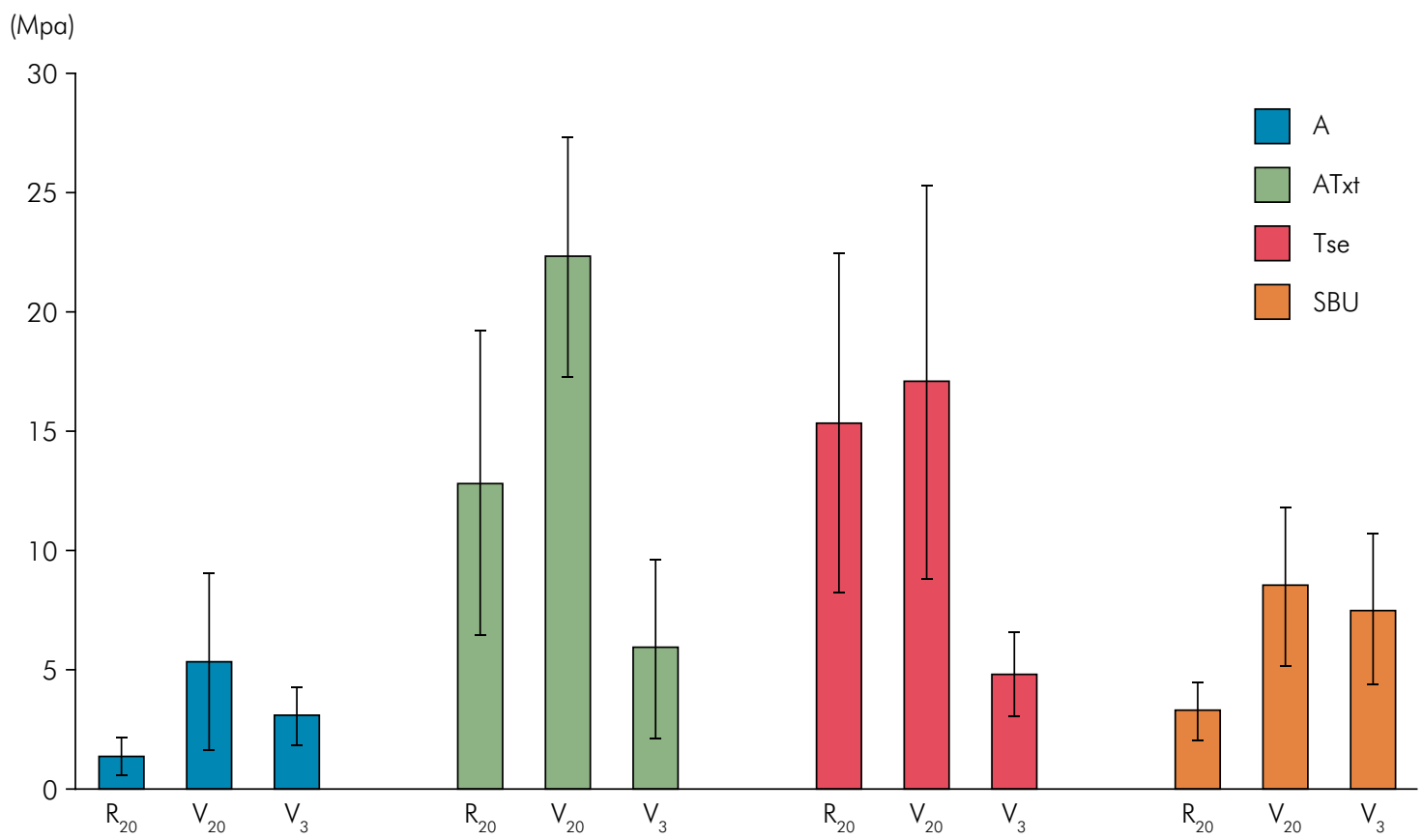

Figure 2. Bond strength values $(\mathrm{MPa}) \pm$ standard deviation, according to "surface treatment" (A, ATxt, Tse, SBU) and "polymerization" $\left(R_{20}, V_{20}, V_{3}\right)$ factors. 
and 5 , and 2 and 5 . Score 2 was the most prevalent for surface treatments $A(n=12)$ and $\operatorname{ATxt}(n=19)$ and score 4 for Tse $(n=13)$ and SBU $(n=12)$ groups. As for the polymerization protocol, score 4 was the most prevalent in groups $R_{20}(n=16)$, while score 2 was more prevalent in groups $V_{20}(n=20)$ and $V_{3}(n=20)$. There was no significant difference between scores 2 and $4(p=1.000)$. Table 4 describes the distribution of ARI scores after the shear bond strength test by experimental group.

\section{Degree of conversion}

The ANOVA results for degree of conversion are presented in Table 5. Mean values were significantly

Table 4. Distribution of ARI scores after shear bond strength test by experimental group $(n, \%)$.

\begin{tabular}{ccccccc}
\hline Group & Score 1 & Score 2 & Score 3 & Score 4 & Score 5 \\
\hline A & $R_{20}$ & $0(0 \%)$ & $1(10 \%)$ & $4(40 \%)$ & $5(50 \%)$ & $0(0 \%)$ \\
& $V_{20}$ & $0(0 \%)$ & $8(80 \%)$ & $1(10 \%)$ & $1(10 \%)$ & $0(0 \%)$ \\
& $V_{3}$ & $0(0 \%)$ & $3(30 \%)$ & $2(20 \%)$ & $5(50 \%)$ & $0(0 \%)$ \\
& $R_{20}$ & $0(0 \%)$ & $3(30 \%)$ & $0(0 \%)$ & $7(70 \%)$ & $0(0 \%)$ \\
ATxt & $V_{20}$ & $0(0 \%)$ & $6(60 \%)$ & $0(0 \%)$ & $4(40 \%)$ & $0(0 \%)$ \\
& $V_{3}$ & $0(0 \%)$ & $10(100 \%)$ & $0(0 \%)$ & $0(\%)$ & $0(0 \%)$ \\
& $R_{20}$ & $0(0 \%)$ & $5(50 \%)$ & $2(20 \%)$ & $3(30 \%)$ & $0(0 \%)$ \\
Tse & $V_{20}$ & $0(0 \%)$ & $6(60 \%)$ & $0(0 \%)$ & $4(40 \%)$ & $0(0 \%)$ \\
& $V_{3}$ & $0(0 \%)$ & $1(10 \%)$ & $3(30 \%)$ & $6(60 \%)$ & $0(0 \%)$ \\
& $R_{20}$ & $0(0 \%)$ & $1(10 \%)$ & $8(80 \%)$ & $1(10 \%)$ & $0(\%)$ \\
SBU & $V_{20}$ & $0(0 \%)$ & $0(0 \%)$ & $1(10 \%)$ & $9(90 \%)$ & $0(0 \%)$ \\
& $V_{3}$ & $0(0 \%)$ & $6(60 \%)$ & $2(20 \%)$ & $2(20 \%)$ & $0(0 \%)$ \\
\hline
\end{tabular}

Score 1: all resin in enamel, Score 2: more than $90 \%$ resin in enamel, Score 3: between $10 \%$ and $90 \%$ resin in enamel, Score 4 : less than $10 \%$ resin in enamel, Score 5: no resin in the enamel. affected by the "polymerization" ( $\mathrm{p}<0.05)$ and "surface treatment" $(p<0.05)$ factors. The interaction between factors was also statistically significant $(\mathrm{p}<0.05)$.

The mean and standard deviations for degree of conversion are shown in Table 6 . The $\mathrm{R}_{20}$ polymerization protocol promoted statistically higher degree of conversion $\left(66.67 \%^{\mathrm{A}}\right)$ than $\mathrm{V}_{20}\left(58.48 \%{ }^{\mathrm{B}}\right)$ and $\mathrm{V}_{3}\left(45.1 \%^{\mathrm{C}}{ }^{\mathrm{C}}\right)$, which are statistically different from each other. Regarding the "surface treatment" factor, SBU $\left(63.84 \%^{\mathrm{A}}\right)$ generated similar values of conversion to ATxt $\left(59.71 \%^{\mathrm{A}}\right)$, which were statistically superior to A group $\left(52.01 \%{ }^{\mathrm{B}}\right)$ and Tse group $\left(51.47 \%{ }^{\mathrm{B}}\right)$. The highest degrees of conversion were obtained for the Tse $/ R_{20}\left(82.3 \%^{\mathrm{A}}\right), \mathrm{SBU} / \mathrm{R}_{20}\left(69.73 \%{ }^{\mathrm{AB}}\right)$, and $S B U / \mathrm{V}_{20}\left(68.35 \%{ }^{\mathrm{ABC}}\right)$ groups. The lowest values were obtained for Tse $/ \mathrm{V}_{20}(49.38 \% \mathrm{D})$ and $\mathrm{A} / \mathrm{R}_{20}\left(49.96 \%^{\mathrm{D}}\right)$ groups.

\section{Power of polymerization units}

Table 7 shows the activation time used, the power reported by the manufacturer and the power verified

Table 5. ANOVA results for the "polymerization" and "surface treatment" factors according to the degree of conversion $\left({ }^{*} \mathrm{p}<0.05\right)$.

\begin{tabular}{|c|c|c|c|c|c|}
\hline Factors & $\mathrm{GL}$ & $S Q$ & $M Q$ & L & $p$ \\
\hline Polymerization & 3 & 3282.2 & 1094.05 & 9.79 & $0.0001^{*}$ \\
\hline Surface treatment & 2 & 9461.0 & 4730.52 & 42.33 & $0.0001^{*}$ \\
\hline $\begin{array}{l}\text { Polymerization* } \\
\text { surface treatment }\end{array}$ & 6 & 10806.7 & 1801.11 & 16.12 & $0.0001^{*}$ \\
\hline Error & 108 & 12070.2 & 111.76 & & \\
\hline Total & 119 & 35620.0 & & & \\
\hline
\end{tabular}

$\mathrm{GL}$ : degree of freedom; SQ: sum of squares; $M Q$ : mean squares; L: freedom. ${ }^{*}$ Statistically significant difference at the $5 \%$ level.

Table 6. Degree of conversion (\%) according to the factors "surface treatment" and "polymerization" $(\mathrm{n}=10)$.

\begin{tabular}{|c|c|c|c|}
\hline Group & Surface treatment & Polymerization & Mean \pm DP \\
\hline $\mathrm{A} / \mathrm{R}_{20}$ & & Radii $20 \mathrm{~s}$ & $49.96 \pm 9.41^{D}$ \\
\hline $\mathrm{A} / \mathrm{N}_{20}$ & Phosphoric Acid 37\% & Valo $20 \mathrm{~s}$ & $55 \pm 1223^{\mathrm{BCD}}$ \\
\hline $\mathrm{A} / \mathrm{N}_{3}$ & & Valo $3 \mathrm{~s}$ & $51.07 \pm 6.47^{D}$ \\
\hline $\mathrm{AT} x \mathrm{t} / \mathrm{R}_{20}$ & & Radii $20 \mathrm{~s}$ & $64.68 \pm 2.7^{\mathrm{BCD}}$ \\
\hline ATxt $/ \mathrm{N}_{20}$ & Phosphoric Acid 37\% + Transbond XT Primer ${ }^{\circledR}$ & Valo $20 \mathrm{~s}$ & $61.2 \pm 1731^{\mathrm{BCD}}$ \\
\hline $\mathrm{ATxt} / \mathrm{N}_{3}$ & & Valo $3 \mathrm{~s}$ & $53.26 \pm 1329 \mathrm{CD}$ \\
\hline $\mathrm{Tse}_{\mathrm{se}} / \mathrm{R}_{20}$ & & Radii $20 \mathrm{~s}$ & $82.3 \pm 13.48^{A}$ \\
\hline $\mathrm{Tse}_{\mathrm{se}} \mathrm{V}_{20}$ & Transbond Plus Self Etching Primer ${ }^{\circledR}$ & Valo $20 \mathrm{~s}$ & $49.38 \pm 13.32^{D}$ \\
\hline $\mathrm{Tse}_{\mathrm{Te}} \mathrm{N}_{3}$ & & Valo $3 \mathrm{~s}$ & $22.73 \pm 9.34^{\mathrm{E}}$ \\
\hline $\mathrm{SBU} / \mathrm{R}_{20}$ & & Radii $20 \mathrm{~s}$ & $69.73 \pm 3.91^{\mathrm{AB}}$ \\
\hline $\mathrm{SBU} / \mathrm{N}_{20}$ & Scotchbond Universa ${ }^{\circledR}$ & Valo $20 \mathrm{~s}$ & $68.35 \pm 7.43^{\mathrm{ABC}}$ \\
\hline $\mathrm{SBU} / \mathrm{N}_{3}$ & & Valo $3 \mathrm{~s}$ & $53.45 \pm 7.70^{C D}$ \\
\hline
\end{tabular}

Tukey's test ( $p<0.05 \%)$; Equal letters indicate statistical similarity. 
Effect of different bonding protocols on degree of monomer conversion and bond strength between orthodontic brackets and enamel

Table 7. Power of the polymerization units according to the manufacturer and the calibration in the radiometer.

\begin{tabular}{lccc}
\hline Polymerization unit & $\begin{array}{c}\text { Time } \\
\text { (seconds) }\end{array}$ & $\begin{array}{c}\text { Power (according to the manufacturer) } \\
\left(\mathrm{mW} / \mathrm{cm}^{2}\right)\end{array}$ & $\begin{array}{c}\text { Power (according to the radiometer } \\
\left(\mathrm{mW} / \mathrm{cm}^{2}\right)\end{array}$ \\
\hline Radii Cal $^{\circledast}$ & 20 & 1200 & 1000 \\
Valo Cordless $^{\circledR}$ & 20 & 1000 & 1100 \\
Valo Cordless $^{\circledR}$ & 3 & 3200 & 2600 \\
\hline
\end{tabular}

by measuring the radiometer for each polymerization unit tested in the study.

\section{Sample power}

Considering the mean difference between the ATxt $/ R_{20}$ group and the Tse/ $V_{3}$ group, with $95 \%$ confidence interval, the power of the sample for the shear bond strength test was estimated at $96.3 \%$, and at $100 \%$ for the degree of conversion.

\section{Discussion}

Prior to the shear test, the samples were stored for 6 months in distilled water at $37^{\circ} \mathrm{C}$. Several studies described shorter storage times such as 24 hours $^{3,4,10,12}$ and 30 days $^{16}$, especially those testing orthodontic bracket adhesion. However, according to some authors, ${ }^{22}$ bond strength decreases after 6 months of water storage. It is believed that water storage promotes a decrease in adhesion due to degradation of the adhesive interface components by hydrolysis. ${ }^{23}$ In addition, water may also infiltrate and weaken the mechanical properties of the polymer matrix. ${ }^{24}$ Another widely reported aging technique is thermocycling. ${ }^{25-6}$ According to the literature, ${ }^{27}$ both thermocycling and water storage are efficient in vitro methods to simulate the performance of dental materials in vivo.

Based on the main results presented in this study, the hypothesis that the surface treatment influences the adhesive strength of metallic brackets bonded to enamel was accepted. The groups treated with 37\% phosphoric acid and no adhesive (A group), showed the lowest adhesive strength values (between 1.27 and 5.28 $\mathrm{MPa}$ ), independent of the polymerization unit used; the values achieved are considered insufficient for orthodontic purposes. ${ }^{15}$ This contradicts the findings of Altmann et al. ${ }^{14}$ and Bazargani et al., ${ }^{13}$ which suggest that adhesive application is a dispensable step during orthodontic bonding. However, Altmann et al. ${ }^{14}$ drew their conclusions from a systematic review in which they included in vitro studies that evaluated immediate bond strength, while the results of this study were obtained after 6 months of storage in water. The study by Bazargani et al. ${ }^{13}$ consisted of a clinical trial assessing failure rates over a 2-year period in young patients, and found significantly different rates between groups that used adhesive $(4.1 \%)$ or not $(12.1 \%)$.

The use of phosphoric acid followed by adhesive application (ATxt) is the treatment recommended by most clinical studies in the area. ${ }^{19,28}$ The adhesive resistance values for this protocol suffered significant variations according to the polymerization unit used. This was evidenced in the samples submitted to 20-second polymerization either by Radii-Call or Valo Cordless, with averages very close to or greater than $13 \mathrm{MPa}$. According to the literature, ${ }^{29}$ values higher than $13 \mathrm{MPa}$ might increase the risk of enamel rupture, since the cohesive forces of enamel can be exceeded. Only the group polymerized by Valo Cordless for 3 seconds approached the clinically acceptable ${ }^{15}$ range of 6 to $8 \mathrm{MPa}$, as opposed to the results presented by Oz et al. ${ }^{4}$ and Lee et al., ${ }^{30}$ who reported averages of 11.43 MPa and $16 \mathrm{MPa}$, respectively for the Radii-Call and Valo Cordless. The difference is probably because the two studies evaluated adhesive resistance after a very short storage period ( 24 hours). In addition, Lee et al. ${ }^{30}$ used two exposures of 3 seconds each, whereas this study used a single exposure of 3 seconds.

Regarding the adhesive resistance of the groups treated with the orthodontic self-etching adhesive system (Tse), averages higher than $13 \mathrm{MPa}$ (above the ideal resistance) were observed with a 20-second polymerization. However, in spite of these values, no fractures were observed in enamel according to the Adhesive Remnant Index. Torres et al., ${ }^{26}$ using similar 
curing time and equipment, reported similarly high averages in groups submitted to aging. The values obtained with Tse cured for 3 seconds in this study were insufficient for orthodontic bonding. ${ }^{15}$

When comparing adhesive resistance between the conventionally treated groups (ATxt) and the orthodontic self-conditioning system (Tse) for each polymerization units, no difference was found, thus corroborating the findings of previous studies. ${ }^{12,26,31}$ No previous study compared ATxt and Tse surface treatments submitted to 3-second curing.

The self-etching adhesive system SBU, unlike Tse, was not specifically developed for orthodontic use, being used in dental substrates, methacrylate-based materials, zirconia ceramics, and metal alloys. ${ }^{32}$ It consists of three chemical components: methacrylate monomers, silane and phosphate monomers. ${ }^{33}$ According to the manufacturer, the MDP phosphate monomer allows greater adhesion to the enamel, and can be used as a metallic primer, resulting in greater adhesion in the self-conditioning technique. Despite this, the groups treated with SBU did not show adhesive resistance values above the acceptable limit; results were similar to samples treated with phosphoric acid alone when using the same polymerization units. However, it is important to note that SBU and polymerization with the Valo unit (independent of time) yield clinically acceptable results, differently from samples treated with acid alone, which showed insufficient values of resistance, ${ }^{15}$ independent of the polymerization protocol (unit and time).

The second hypothesis tested in this study was also accepted, as the polymerization protocol influenced the adhesive strength of metallic brackets bonded to enamel. Radii Call is a conventional polymerization unit that emits light intensity of around 1000 to 1250 $\mathrm{mW} / \mathrm{cm}^{2}$ and is suitable for use when working with 20-second applications. ${ }^{4}$ The Valo Cordless can function as a conventional unit when working in the standard mode, with $1000 \mathrm{~mW} / \mathrm{cm}^{2}$ (according to the manufacturer) and $1100 \mathrm{~mW} / \mathrm{cm}^{2}$ (according to the radiometer) emissions. The unit can also emit high light intensities in the extra-power mode, which emits $3200 \mathrm{~mW} / \mathrm{cm}^{2}$ according to the manufacturer, but only $2600 \mathrm{~mW} / \mathrm{cm}^{2}$ according to the radiometer. According to the manufacturers, these high-intensity units can polymerize brackets in 3 to 6 seconds. ${ }^{25}$ However, other authors ${ }^{34}$ believe that the exaggerated acceleration of chemical reactions may increase polymerization stress and interfere with enamel bonding.

In general, the highest values of adhesive strength were obtained with the Valo unit in the standard mode (20 seconds), but values were mostly similar to those obtained by the Radii unit (20 seconds). The exception was in the conventionally treated group (ATxt). When comparing 3 - and 20-second curing times, independent of the polymerization unit, strength values were significantly different in groups ATxt and Tse. Previous studies ${ }^{4,19}$ evaluating the Valo unit in the extra-power mode performed conventional enamel surface treatment in all groups (ATxt). For example, when comparing Valo (3200 mW/cm², 3 seconds) and Elipar S10 $\left(1600 \mathrm{~mW} / \mathrm{cm}^{2}\right.$, 10 seconds), Oz et al. ${ }^{4}$ found no difference in adhesive strength in vitro, or in clinical failure rates observed over 12 months. Ward et al. ${ }^{19}$ compared standard and extrapower modes of the Valo unit and found no difference in clinical failure rates. However, these authors performed the extra-power mode polymerization for 6 seconds rather than 3 seconds as in the present study, which obtained significantly different adhesive strength values for the Valo for 20 seconds, the Radii for 20 seconds and the Valo for 3 seconds.

It is important to elucidate that desirable values of bracket adhesion parameters, mentioned throughout the discussion, were obtained from classic works. ${ }^{15,29}$ However, they are little old manuscripts and provide information based on clinical situations that have been altered over time. Therefore, it is necessary to consider the temporal limitation of these parameters.

Overall, the evaluation of the Adhesive Remnant Index (ARI) in this study showed a predominance of score 2 in certain tests, and score 4 in others. Score 4 predominated in the $\mathrm{A} / \mathrm{R}_{20}$ and $\mathrm{A} / \mathrm{V}_{3}$ groups, indicating a weaker adhesion in the adhesive resin-enamel interface. This corroborates the low bond strength values obtained in the shear test and reinforces the hypothesis that the acid-only surface treatment causes insufficient adhesion between adhesive resin and enamel. The exception was in the $A / V_{20}$ group, which showed a strong predominance of score 2 , again in agreement with the results of the shear test, which showed higher bond strength values in this group. 
Score 2 was more frequently observed in most of the conventionally treated groups (ATxt/ $\mathrm{V}_{20}$ and $\mathrm{ATxt} / \mathrm{V}_{3}$ ), showing a predominance of resin-bracket interface failures. According to Usumez (2002), ${ }^{35}$ the literature is controversial as to the most desirable type of failure. Some authors ${ }^{36}$ suggest that a smaller amount of adhesive remaining in the enamel results in a shorter clinical time for cleaning and polishing the teeth after brackets removal. However, other authors ${ }^{37}$ prefer having a greater amount of adhesive remnant on the enamel surface, as the residues can be carefully removed with specific burs and this prevents cracks and fractures. This seems contradictory, considering that higher bond strength values in lower ARI scores, in general. Therefore, a greater amount of adhesive in enamel is associated with cracks and fractures of enamel during bracket removal. ${ }^{15}$

The hypotheses that "surface treatment" and "polymerization" influence the degree of conversion of bonding agents were also accepted, as well as the existence of the interaction between both factors. In general, most of the groups showed low degree of conversion values (between $49.38 \%$ and $69.73 \%$ ). This results might have been found because the degree of conversion was measured at the site where the center of the bracket base had been positioned, i.e. where light incidence is the lowest. ${ }^{38}$ In addition, most studies reporting degree of conversion perform the polymerization without the bracket in place, yielding values that do not reflect clinical reality. ${ }^{39}$

According to some authors, ${ }^{39}$ a higher unit power results in a higher degree of conversion. Nonetheless, other authors ${ }^{40}$ have concluded that time is more important than power for conversion of the monomers into polymers. In our study, no difference was observed between the degree of conversion when comparing groups $\mathrm{V}_{20}$ and $\mathrm{V}_{3}$; therefore, it is believed that the higher power in the polymerization unit was sufficient to compensate the reduction in polymerization time.

The Tse group was the most affected by different polymerization protocols. The degree of conversion ranged from $22.73 \%$ to $82.3 \%$ and was statistically different among $\mathrm{R}_{20}, \mathrm{~V}_{20}$ and $\mathrm{V}_{3}$ groups. Shear bond strength values also showed significant variation (between 4.75 MPa and 17.05 MPa), which corroborates the theory that Tse appears to be more sensitive to polymerization protocol variations than the other surface treatments.

Finally, the results discussed herein are extremely important for evaluating the adhesive strength of metallic brackets bonded to enamel using different surface treatments and polymerization protocols, as well as the degree of conversion of the tested agents. However, the findings need to be complemented and validated through clinical trials.

\section{Conclusions}

Surface treatment and polymerization protocol influence both adhesive strength and the degree of conversion during metal bracket bonding to enamel; the treatment with self-etching primer is more sensitive to variations in polymerization protocols than the other surface treatments. Using phosphoric acid alone does not provide suitable bond strength or degree of conversion for bonding metal brackets to enamel.

\section{References}

\footnotetext{
1. Wang $\mathrm{CH}$, Randazzo L. Evolution of imaging and management systems in orthodontics. Am J Orthod Dentofacial Orthop. 2016 Jun;149(6):798-805. https://doi.org/10.1016/i.ajodo.2016.03.016

2. Takaki T, Tamura N, Yamamoto M, Takano N, Shibahara

$T$, Yasumura $T$ et al. Clinical study of temporary anchorage devices for orthodontic treatment: stability of micro/mini-screws and mini-plates: experience with 455 cases. Bull Tokyo Dent Coll. 2010;51(3):151-63. https://doi.org/10.2209/tdcpublication.51.151
}

3. Goswami A, Mitali B, Roy B. Shear bond strength comparison of moisture-insensitive primer and selfetching primer. J Orthod Sci. 2014 Jul;3(3):89-93. https://doi.org/10.4103/2278-0203.137695

4. Oz AA, Oz AZ, Arici S. In-vitro bond strengths and clinical failure rates of metal brackets bonded with different light-emitting diode units and curing times. Am J Orthod Dentofacial Orthop. 2016 Feb;149(2):212-6. https://doi.org/10.1016/j.ajodo.2015.07.036 
5. Songra G, Clover M, Atack NE, Ewings P, Sherriff M, Sandy JR et al. Comparative assessment of alignment efficiency and space closure of active and passive selfligating vs conventional appliances in adolescents: a single-center randomized controlled trial. Am J Orthod Dentofacial Orthop. 2014 May;145(5):569-78. https://doi.org/10.1016/i.ajodo.2013.12.024

6. Bellini H, Moyano J, Gil J, Puigdollers A. Comparison of the superelasticity of different nickel-titanium orthodontic archwires and the loss of their properties by heat treatment. J Mater Sci Mater Med. 2016 Oct;27(10):158. https://doi.org/10.1007/s10856-016-5767-5

7. Dominguez GC, Tortamano A, Lopes LV, Catharino PC, Morea C. A comparative clinical study of the failure rate of orthodontic brackets bonded with two adhesive systems: conventional and self-etching primer (SEP). Dental Press J Orthod. 2013 Mar-Apr;18(2):55-60. https://doi.org/10.1590/S2176-94512013000200014

8. Mohammed RE, Abass S, Abubakr NH, Mohammed ZM. Comparing orthodontic bond failures of lightcured composite resin with chemical-cured composite resin: A 12-month clinical trial. Am J Orthod Dentofacial Orthop. 2016 Aug;150(2):290-4. https://doi.org/10.1016/i.ajodo.2016.02.013

9. Buonocore MG. A simple method of increasing the adhesion of acrylic filling materials to enamel surfaces. J Dent Res. 1955 Dec;34(6):849-53. https://doi.org/10.1177/00220345550340060801

10. Grünheid T, Larson BE. Grünheid T, Larson BE. Repeated bracket bonding: conventional or selfetching primer? J World Fed Orthod. 2014;3(3):102-5. https://doi.org/10.1016/j.ejwf.2014.05.001

11. Esteves CM, Ota-Tsuzuki C, Reis AF, Rodrigues JA. Antibacterial activity of various self-etching adhesive systems against oral streptococci. Oper Dent. $2010 \mathrm{Jul}-$ Aug;35(4):448-53. https://doi.org/10.2341/09-297-L

12. Yadala C, Gaddam R, Arya S, Baburamreddy KV, Raju VR, Varma PK. Comparison of Shear Bond Strength of Three Selfetching Adhesives: An In-Vitro Study. J Int Oral Health. 2015 Jul;7(7):53-7.

13. Bazargani F, Magnuson A, Löthgren H, Kowalczyk A. Orthodontic bonding with and without primer: a randomized controlled trial. Eur J Orthod. 2016 Oct;38(5):503-7. https://doi.org/10.1093/ejo/cjv075

14. Altmann AS, Degrazia FW, Celeste RK, Leitune VC, Samuel SM, Collares FM. Orthodontic bracket bonding without previous adhesive priming: A meta-regression analysis. Angle Orthod. 2016 May;86(3):391-8. https://doi.org/10.2319/041615-255.1

15. Whitlock BO 3rd, Eick JD, Ackerman RJ Jr, Glaros AG, Chappell RP. Shear strength of ceramic brackets bonded to porcelain. Am J Orthod Dentofacial Orthop. 1994 Oct;106(4):358-64. https://doi.org/10.1016/S0889-5406(94)70056-7
16. Lowder PD, Foley T, Banting DW. Bond strength of 4 orthodontic adhesives used with a caries-protective resin sealant. Am J Orthod Dentofacial Orthop. 2008 Aug;134(2):291-5. https://doi.org/10.1016/i.ajodo.2008.03.002

17. Pinto CM, Ferreira JT, Matsumoto MA, Borsatto MC, Silva RA, Romano FL. Evaluation of different LED light-curing devices for bonding metallic orthodontic brackets. Braz Dent J. 2011;22(3):249-53. https://doi.org/10.1590/S0103-64402011000300012

18. McCusker N, Lee SM, Robinson S, Patel N, Sandy JR, Ireland AJ. Light curing in orthodontics; should we be concerned? Dent Mater. 2013 Jun;29(6):e85-90. https://doi.org/10.1016/j.dental.2013.03.023

19. Ward JD, Wolf BJ, Leite LP, Zhou J. Clinical effect of reducing curing times with high-intensity LED lights. Angle Orthod. $2015 \mathrm{Nov} ; 85(6): 1064-9$. https://doi.org/10.2319/080714-556.1

20. International Organization for Standardization. ISO/TS 11405.:2003. Dentistry: testing of adhesion to tooth structure. Geneva: International Organization for Standardization; 2003.

21. Bishara SE, Trulove TS. Comparisons of different debonding techniques for ceramic brackets: an in vitro study. Part II. Findings and clinical implications. Am J Orthod Dentofacial Orthop. 1990 Sep;98(3):263-73. https://doi.org/10.1016/S0889-5406(05)81604-X

22. Costa AR, Correr AB, Consani $S$, Giorgi MC, Vedovello $S A$, Vedovello Filho $M$ et al. Influence of Water storage and bonding material on bond strength of metallic brackets to ceramic. Braz Dent J. 2015 Oct;26(5):503-6. https://doi.org/10.1590/0103-6440201300403

23. De Munck J, Van Landuyt K, Peumans M, Poitevin A, Lambrechts $P$, Braem $M$ et al. A critical review of the durability of adhesion to tooth tissue: methods and results. J Dent Res. 2005 Feb;84(2):11832. https://doi.org/10.1177/154405910508400204

24. Ito $S$, Hashimoto $M$, Wadgaonkar B, Svizero N, Carvalho RM, Yiu $C$ et al. Effects of resin hydrophilicity on water sorption and changes in modulus of elasticity. Biomaterials. 2005 Nov;26(33):6449-59. https://doi.org/10.1016/j.biomaterials.2005.04.052

25. Cerekja E, Cakirer B. Effect of short curing times with a high-intensity light-emitting diode or high-power halogen on shear bond strength of metal brackets before and after thermocycling. Angle Orthod. 2011 May;81(3):510-6. https://doi.org/10.2319/071810-412.1

26. Torres LS, Alves LA, Fava M, Di Nicoló R. Effects of thermomechanical and thermocycling on the shear bond strength of brackets to bovine enamel bonded with conventional and self-etching adhesive systems. Braz Dent Sci. 2015;18(3):98106. https://doi.org/10.14295/bds.2015.v18i3.1152

27. Yuasa T, lijima M, Ito S, Muguruma T, Saito T, Mizoguchi I. Effects of long-term storage and thermocycling on bond strength of two self-etching primer adhesive systems. Eur J Orthod. 2010 Jun;32(3):285-90. https://doi.org/10.1093/ejo/cjp118 
28. Pandis N, Strigou S, Eliades T. Long-term failure rate of brackets bonded with plasma and high-intensity light-emitting diode curing lights: a clinical assessment. Angle Orthod. 2007 Jul;77(4):707-10. https://doi.org/10.2319/062106-253

29. Brown CR, Way DC. Enamel loss during orthodontic bonding and subsequent loss during removal of filled and unfilled adhesives. Am J Orthod. $1978 \mathrm{Dec} ; 74(6): 663-71$. https://doi.org/10.1016/0002-9416(78)90005-2

30. Lee HM, Kim SC, Kang KH, Chang NY. Comparison of the bonding strengths of second- and thirdgeneration light-emitting diode light-curing units. Korean J Orthod. 2016 Nov;46(6):364-71. https://doi.org/10.4041/kjod.2016.46.6.364

31. Fleming PS, Johal A, Pandis N. Self-etch primers and conventional acid-etch technique for orthodontic bonding: a systematic review and meta-analysis. Am J Orthod Dentofacial Orthop. 2012 Jul;142(1):83-94. https://doi.org/10.1016/j.ajodo.2012.02.023

32. Muñoz MA, Luque I, Hass V, Reis A, Loguercio AD, Bombarda NH. Immediate bonding properties of universal adhesives to dentine. J Dent. 2013 May;41(5):404-11. https://doi.org/10.1016/j.jdent.2013.03.001

33. Kim JH, Chae SY, Lee Y, Han GJ, Cho BH. Effects of multipurpose, universal adhesives on resin bonding to zirconia ceramic. Oper Dent. 2015 Jan-Feb;40(1):55-62. https://doi.org/10.2341/13-303-L

34. Gonçalves LS, Moraes RR, Ogliari FA, Boaro L, Braga RR, Consani S. Improved polymerization efficiency of methacrylate-based cements containing an iodonium salt. Dent Mater. 2013 Dec;29(12):1251-5. https://doi.org/10.1016/j.dental.2013.09.010

35. Uşümez S, Orhan M, Uşümez A. Laser etching of enamel for direct bonding with an $\mathrm{Er}, \mathrm{Cr}: Y S G G$ hydrokinetic laser system. Am J Orthod Dentofacial Orthop. 2002 Dec;122(6):649-56. https://doi.org/10.1067/mod.2002.127294

36. Çokakoğlu S, Nalçacı R, Üşümez S, Malkoç S. Effect of different combinations of $\mathrm{Er}$ : YAG laser-adhesives on enamel demineralization and bracket bond strength. Photomed Laser Surg. 2016;34(4):164-70. https://doi.org/10.1089/pho.2015.4041

37. Raii SH, Birang R, Maidzade F, Ghorbanipour R. Evaluation of shear bond strength of orthodontic brackets bonded with Er-YAG laser etching. Dent Res J (Isfahan). 2012 May;9(3):288-93.

38. Yoshida S, Namura Y, Matsuda M, Saito A, Shimizu N. Influence of light dose on bond strength of orthodontic light-cured adhesives. Eur J Orthod. 2012 Aug;34(4):493-7. https://doi.org/10.1093/ejo/cir051

39. Amato PA, Martins RP, dos Santos Cruz CA, Capella MV, Martins LP. Time reduction of light curing: influence on conversion degree and microhardness of orthodontic composites. Am J Orthod Dentofacial Orthop. 2014 Jul;146(1):40-6. https://doi.org/10.1016/i.ajodo.2014.03.022

40. Verma P. Curing efficiency of three light emitting diode units at different curing profiles. Indian J Dent Res. 2016 Mar-Apr;27(2):168-73. https://doi.org/10.4103/0970-9290.183134 